\title{
TESTING THE LIMITS OF LIBERALISM: A REVERSE CONJECTURE
}

\author{
ALI M. RIZVI \\ Universiti Brunei Darussalam, Brunei
}

In this paper, I propose to look closely at certain crucial aspects of the logic of Rawls' argument in Political Liberalism and related subsequent writings. Rawls' argument builds on the notion of comprehensiveness, whereby a doctrine encompasses the full spectrum of the life of its adherents. In order to show the mutual conflict and irreconcilability of comprehensive doctrines, Rawls needs to emphasise the comprehensiveness of doctrines, as their irreconcilability to a large extent emanates from that comprehensiveness. On the other hand, in order to show the possibility and plausibility of the political liberal solution he needs to emphasise that most of these doctrines are reasonable: i.e., they are willing to cede a portion of their authority to political liberalism for the right reasons. Yet, if they are willing to cede a portion of their authority to a political conception they cannot be as comprehensive as we initially thought they were. All these elements highlight the tension in the argument itself. I suggest that many of these tensions can be removed by making Rawls' account more flexible. In this context I propose certain amendments to Rawls' account, which may overcome some of the tensions mentioned above.

\section{FROM A THEORY OF JUSTICE TO POLITICAL LIBERALISM}

Intuitions about diversity or lack thereof in the modern world vary greatly. ${ }^{1}$ Some interpreters marvel at the immense diversity and plurality of modern societies (and at times are even frightened by it). Others are less dazzled by appearances, and fix their gaze on the ultimate one-dimensionality of globalisation-driven modern cultures and societies. John Rawls can be counted among the former. He moves from his position in $A$ Theory of Justice $^{2}$ to a new but related position in Political Liberalism ${ }^{3}$ in part because in his view $A$ Theory of Justice had not sufficiently taken into account the fact of modern pluralism. ${ }^{4}$ The pluralism of modern life, for Rawls, is not threatening on its own, however. It becomes (potentially) threatening only when combined with other facts ${ }^{5}$ of modern life, especially life in constitutional democracies. The most important of these facts are the freedom and equality of every citizen as the supreme value of political organisation.

The basic question for Rawls is how to reconcile, and not just to conform, this belief in freedom and equality with the immense diversity of modern life. The inevitable imperatives of security and political order (in the face of the spectre of anarchy which the allusion to modern diversity implicitly invokes) require that diverse elements of a modern society must have at least some minimum consensus around which political life could be organised; while adherence to the supreme values of freedom and equality demands that the diversity of modern life must not be sacrificed at the altar of order. Rawls' claim, however, is not just that order should not come at the expense of freedom, but also that one cannot establish order in the modern world based on comprehensive doctrines without the use of immense force and oppression. ${ }^{6}$ This is the second spectre which haunts Rawls' later political theory: the spectre of oppression. ${ }^{7}$ 
The most fascinating aspect of Rawls' account in Political Liberalism is that the comprehensive doctrines he is talking about include not just comprehensive, illiberal and totalitarian doctrines but also liberal ones, including his own position set out in $A$ Theory of Justice. ${ }^{8}$ What Rawls is now claiming is that even an attempt to organise a society based on the principles laid down in $A$ Theory of Justice would require an immense use of oppressive force. Of course, Rawls is not withdrawing from his claims in $A$ Theory of Justice tout court, but what he is saying is that if a political society is to be organised on those principles, those principles must be defended on some 'doctrine neutral' ${ }^{9}$ grounds rather than on the basis of a comprehensive Kantian moral doctrine, as they are so defended in $A$ Theory of Justice. For sure, Rawls as a private citizen, as an academic, may continue to defend those principles on the basis of any comprehensive doctrine (perhaps as long as they are reasonable), but if he wishes to intervene in political debates in the forum of public reason (which involves society's political institutions, such as parliament, executives, the judiciary and political campaigns, as well as citizens in their capacity as 'hypothetical' legislators) ${ }^{10}$ he must defend those principles in political (doctrine-neutral) terms rather than with reference to his preferred comprehensive doctrine. This involves 'translating' debates couched in a comprehensive language into political language. ${ }^{11}$

In this context, Rawls raises an interesting question: how to reconcile political liberalism with comprehensive doctrines which are illiberal ${ }^{12}$ in many of their claims (though they may be reasonable). The crucial question is: why would a comprehensive doctrine, which is essentially non-liberal, join forces with political liberalism in founding a liberal society (or becoming a partner in such a society)? Rawls' answer, in a nutshell, is that most comprehensive doctrines, even the illiberal ones, are reasonable doctrines. ${ }^{13}$ Their proponents can be persuaded to see the point of political liberalism. ${ }^{14}$ They adopt the core conceptions of political liberalism not on the grounds of a liberal comprehensive doctrine, but in the light of their own respective worldviews. Thus a liberal can defend the principle of tolerance based on human dignity or intrinsic human worth, while the adherent of a comprehensive religious doctrine may defend this very principle on the idea (for example) that all humans are children of God (even those who in fact do not recognise Him as such) and therefore deserve respect and tolerance.

In sum, Rawls claims that it is in the interest of all comprehensive doctrines in modern times to accept political liberalism as the sole possible vision of political organisation. It should be added here, and this is crucial, that Rawls is not saying that comprehensive doctrines should embrace political liberalism as an inevitable compromise; what he is claiming is, rather, that they should do it for the right reasons - that is, out of conviction. ${ }^{15}$ This is what makes Rawls' position so interesting. He concedes that there would still be comprehensive doctrines that would not be able to see any need for rapprochement with political liberalism, let alone adopt it for the right reasons. He terms such doctrines 'unreasonable'. They could exist within a liberal order as long as they do not attempt to disrupt it, in which case they should/would be ruthlessly wiped out (although quite understandably Rawls is not very explicit about this option). ${ }^{16}$

In this paper, I propose to look closely at certain crucial aspects of the logic of Rawls' argument in Political Liberalism and related subsequent writings. The key aspect of Rawls' investigation is what may be termed the dialectic between the notions of 'comprehensive doctrine' and 'political conception'. The plausibility of Rawls' argument in Political Liberalism depends to a large extent on the fine balance that needs to be maintained between an emphasis on irreconcilability among different comprehensive doctrines and an emphasis on their reasonableness. To the extent that comprehensive doctrines are 
reasonable they cannot be absolutely irreconcilable; and to the extent that they are irreconcilable they cannot be regarded as seamlessly reasonable. This tension between irreconcilability and reasonableness is related to other tensions. One is the tension between the 'comprehensiveness' of a comprehensive doctrine and the corresponding (and contrasting) 'restricted' character of the political conception. Rawls' argument builds on the notion of comprehensiveness whereby a doctrine encompasses the full spectrum of the life of its adherents. ${ }^{17}$ In order to show the mutual conflict and irreconcilability of comprehensive doctrines, Rawls needs to emphasise the comprehensiveness of doctrines, as their irreconcilability to a large extent emanates from their comprehensiveness. On the other hand, in order to show the possibility and plausibility ${ }^{18}$ of the political liberal solution he needs to emphasise that most of these doctrines are reasonable, i.e., that they are willing to cede a portion of their authority to political liberalism (or to the political society) for the right reasons. But if they are willing to cede a portion of their authority to a political conception, they cannot be as comprehensive as we initially thought they were (or maybe they are transformed in the process).

Similarly, in order to show that political liberalism is a possible and plausible solution, Rawls emphasises its 'thinness' and 'neutrality' in various ways, for that is one of the crucial grounds on which political liberalism becomes acceptable to all. ${ }^{19}$ Finally, Rawls on the one hand emphasises the non-interfering character of liberalism, which emanates mainly from its thinness - its character as the reconciler of different (potentially) warring factions - while, on the other hand, in order to show that most doctrines accept liberalism for the right reason, he needs to show liberalism's ability (and willingness) to mould the doctrine's character in its own image. All these elements highlight the tension in the argument itself. What I would like to claim, at least initially, is that these tensions necessarily weaken Rawls' position as a whole, and that in order to remove these tensions the argument needs thorough revision. However, as a conciliatory gesture I forgo this strategy and its consequences; instead, I suggest that many of these tensions can be removed by making Rawls' account more flexible.

The structure of the paper is as follows. Section II gives a detailed account of tensions within Political Liberalism mentioned briefly above. Section III suggests certain amendments to Rawls's account, which may overcome some of the tensions mentioned above. In the concluding section I suggest some points for further investigation.

\section{LOGICAL (CONCEPTUAL) TENSIONS WITHIN POLITICAL LIBERALISM}

Rawls rightly thinks that, in order to survive and prosper over time, a liberal regime should be stable, and in order for it to be stable it should be accepted for the right reasons, i.e., it should be a legitimate regime in the eyes of its members. ${ }^{20}$ In other words, a liberal regime can be considered stable only if it has the basic unconditional ${ }^{21}$ loyalty of its members. This, for Rawls, excludes any kind of pragmatic, instrumental loyalty. ${ }^{22}$

The type of legitimacy Rawls envisages for attaining such stability is made clear by his example of the Quakers, whom he treats in the context of his discussion on the distinction between the overall legitimacy of a liberal regime ${ }^{23}$ and the justness of its specific policies. Rawls' aim is to demonstrate that citizens of a liberal regime should support the regime on the basis of its legitimacy, assuming it is founded on the principles of liberty and equality for all citizens, even though not all of its specific laws and injunctions are necessarily just in the eyes of its members. Quakers, as religious people who are against the very concept of 
war, are bound to refuse to engage in any war, and hence will oppose a war waged even by a regime they consider legitimate. However, and this is the point, the act of waging a war, even though it is necessarily unjust in Quakers' eyes, should not lead them to oppose the liberal regime itself or to consider a liberal government illegitimate.

The reason for this lies in the concept of legitimacy itself, which differentiates between the general or foundational justness of a regime and its particular policies. A regime can be just in general while its particular policies are unjust. This is due to two fundamental factors, one of which is general while the other is specific to liberal regimes. The general factor is human fallibility - all human systems, even the ones built on the right principles, are going to make particular mistakes and are going to enact particular laws and pursue policies that are not necessarily just. In a liberal regime the scope of particular unjust polices (seen from the eyes of its citizens) increases tremendously because people underneath its umbrella belong to incredibly diverse and often irreconcilable comprehensive doctrines. Thus fundamental or basic loyalty becomes essential for a liberal regime. ${ }^{24}$

Rawls reserves the question of legitimacy for the third level of justification, ${ }^{25}$ precisely because at this level citizens take into account the fact that there are many other comprehensive doctrines, very different from theirs, which nonetheless support the liberal regime and hence are reasonable. ${ }^{26}$ The mere existence of the plurality of potentially irreconcilable comprehensive doctrines makes the citizens intuitively aware of the great difficulty of reaching consensus on political matters. This realisation paves the way for the understanding that there might be numerous occasions where citizens would have to compromise on specific policies. ${ }^{27}$ Thus, to the question why 'the Quakers' religious doctrine prohibiting their engaging in war does not put their allegiance in doubt' ${ }^{28}$ Rawls' answer would be that since liberalism is supported by Quakerism for its own internal reasons, ${ }^{29}$ and since from the third level of justification we know how hard it is to agree on specific policy matters, a Quaker is able to support a liberal regime as just and legitimate even when she cannot and does not support all its specific policies as legitimate. In a nutshell, the unjustness of specific liberal policies (as long as they are not too grave) ${ }^{30}$ does not undermine their overall justness and legitimacy.

However, note that in taking the above stance a Quaker must make the following two essential assumptions: that the principles on the basis of which she accepts liberalism and/ or the values which are represented by liberalism outweigh the possible infringements of specific Quaker values (such as waging a war) within a liberal regime; and that at least some political values outweigh religious values, so that if the two are in conflict the former will get priority (and this is implicit in the first assumption but should be made explicit). Rawls recognises this when he writes (referring to the third level of justification): ' $\ldots$ we hope that citizens will judge (by their comprehensive view) that political values are normally (though not always) ordered prior to, or outweigh, whatever non-political values may conflict with them'. ${ }^{31}$

With this explanation everything seems to fall in place. Following this, it seems reasonable for a comprehensive doctrine (whether religious or non-religious) to accept political liberalism for the right reasons, assuming the following three important facts to be true: a) political liberalism is based on political (moral) values which represent the core morality of all reasonable religious or non-religious comprehensive doctrines, even though every comprehensive doctrine would defend these values on different moral or metaphysical grounds; b) all reasonable people realise that it is impossible to resolve fundamental disagreements given that we are all free and equal citizens - in other words, we all believe in reasonable pluralism and the burden of judgements; and c) it is hard to 
reach agreement on specific policies given (a) \& (b), thus the need to differentiate between the overall legitimacy of a liberal regime and its specific values. ${ }^{32}$

But the above explanation is reasonable only if it can be proven that Rawls' hope that comprehensive doctrines would order political values - specifically those of freedom and equality - as prior to their own core doctrines and core concerns is not only possible but also (realistically) plausible. ${ }^{33}$ The question of plausibility comes in stark focus in the following fundamental question raised by Rawls:

How is it possible for citizens of faith to be wholehearted members of a democratic society who endorse society's intrinsic political ideals and values and do not simply acquiesce in the balance of political forces? Expressed more sharply: How is it possible - or is it - for those of faith, as well as the nonreligious (secular), to endorse a constitutional regime even when their comprehensive doctrines may not prosper under it, and indeed may decline? ? $^{34}$

To start with, this seems to me in contradiction with the spirit of what Rawls says in the same paper (for example when he assures us that 'no one is expected to put his or her religious or non-religious doctrine in danger'). ${ }^{35}$ Passing over this worry for the moment, the fundamental question is this: why should a doctrine accept its own (possible) decline and give way to constitutional democracy? Moreover, would it infringe the principle of mutuality, for example, if some comprehensive doctrines are asked for more sacrifices than others? Recall that one of the main purposes of Rawls' political liberalism is to show the internal coherence of liberal constitutional democracy under the conditions of reasonable pluralism. ${ }^{36}$ His whole argument depends on the validity of his distinction between the notions of comprehensive doctrine and political conception, which in turn lies in their range of applicability. ${ }^{37} \mathrm{~A}$ comprehensive doctrine is comprehensive precisely because its range of applicability does not allow any exceptions (or if there are any exceptions they are internally sanctioned). Now, for a comprehensive doctrine to become reasonable it may be necessary for it to cede the region of the political to something other than itself (i.e., political liberalism). ${ }^{38}$ The question is whether in the process the comprehensive doctrine will still remain comprehensive. Thus, it is important that Rawls raises the question as to why a comprehensive doctrine should be ready to cede part of its authority to something else in the first place, especially when it may result in the decline of such a doctrine. The answer Rawls gives to the question is as follows:

Here the answer lies in the religious or nonreligious doctrine's understanding and accepting that, except by endorsing a reasonable constitutional democracy, there is no other way fairly to ensure the liberty of its adherents consistent with the equal liberties of other reasonable free and equal citizens. $^{39}$

But this solution presupposes several points on the part of a comprehensive doctrine, and two of them are of prime importance: a) a comprehensive doctrine accepts the doctrine of equal liberty as its own core value; and b) a comprehensive doctrine also accepts that political values trump all other values - specifically, the value of equal liberty trumps all other values. It would seem that if a doctrine accepts (a) \& (b), at least on the face of it, it should already be considered a liberal doctrine. However, Rawls may point out that he requires the acceptance of (a) \& (b) only as political values and not as religious or secular doctrines. What this amounts to is that although he requires all doctrines to accept (a) \& (b), he does not put conditions on the sorts of reasons on which they will base their acceptance of (a) \& (b). A Christian may accept them for Christian reasons; a secular may accept them for secular reasons; and a Muslim may accept them for Islamic reasons, and so on. On this 
interpretation, Rawls' strategy of avoidance is not focused on the values themselves everyone must accept them - rather, the strategy is focused on reasons for accepting those values. ${ }^{40}$ As long as individual doctrines (secular or religious) accept (a) \& (b) based on their own principled internal reasons, it is of no interest to political liberalism to enquire into the nature and quality of those reasons. The last step emanates from political liberalism's avoidance strategy; however, since the avoidance strategy ${ }^{41}$ is embedded in a principled acceptance of political values, it does not degenerate into a modus vivendi; it still remains a principled justification or a principled acceptance of political liberalism.

Thus, the answer to the question why a comprehensive doctrine would accept political liberalism at the peril of its own progress, and at the risk of its own decline, seems to be that it is because the doctrine realises all of the following: a) political values are great values ${ }^{42}$ if people accept these values they are accepting what the doctrine was always already striving for, if for different reasons; b) political values represent the "very condition that make fair social cooperation possible on a footing of mutual respect', ${ }^{43}$ and c) given the fact of the freedom of human reason, which makes agreement on a single doctrine without immense use of oppression (which all great and reasonable comprehensive and semi comprehensive doctrines will certainly abhor and loathe) impossible; and, given the bloody history of religious and non-religious wars, it is feasible to expect that any reasonable, comprehensive doctrine would subordinate all other values to political values (as far as political life and questions of basic structures of a society are concerned) and abandon any values that make such acceptance impossible. Acceptance of (a), (b) \& (c) is sufficient reason for a reasonable doctrine to accept political liberalism as a political framework, even at the peril of its own progress and at the risk of its own decline. ${ }^{44}$

The above explanations seem good enough, but for two further objections: a) a doctrine may accept all the above conditions (a-c), but add the proviso that it is acceptable as long as it does not affect the personal salvation ${ }^{45}$ of its members, because personal salvation (for example) is the most important value and cannot be sacrificed to any other consideration even though other considerations are important and valid. In which case, the concern for salvation may stop a doctrine from accepting the claim that political values should outweigh such concern. ${ }^{46}$ In this context, the onus is on political liberalism to explain why disregarding concern for salvation does not infringe on the requirement of reciprocity (mutuality). ${ }^{47}$ This leads to the second objection: b) while setting out his argument, Rawls declares that the most irresolvable conflicts pertain to deep values (which he contrasts with political values), and that excluding those values from discussions about the basic structure of political society is the first step towards a reasonable (and realistic) consensus on the nature of political society. ${ }^{48}$ This background, however, does not sit well with his further claim that political values should (almost always) trump non-political values. We know Rawls' reasons for this, and they do make sense to a certain extent. However, when taken in the context of Rawls' setting for his argument as a whole, it is hard to reconcile the fact that on the one hand his whole principled-cum-avoidance strategy is premised on the idea that the deepest, most irresolvable conflicts concern 'deep values' (hence we should as much as possible avoid discussing them in the context of the objectives of political liberalism), and on the other that political values should trump these deep values, even though political values are not deep values ${ }^{49}$ (although obviously, at least for Rawls, they are great values) - hence, he assumes that reconciliation is possible by making political values the centre of our intended consensus.

The above tension is due to the fact that Rawls does not explicitly face the dilemmas of his own approach in a straightforward manner. Though he does not claim his political 
liberalism to be neutral in substantive matters, it still carries with it residues of neutrality when it aspires (or claims) to leave 'philosophy as it is' or comprehensive doctrines as they are $^{50}$ The fact of the matter is that it does not leave doctrines as they are, nor can it. To elaborate on this point, let us consider the condition of reasonableness as applied to comprehensive doctrines. One can interpret the requirement in two ways: a) doctrines are reasonable as long as they are not incompatible with the essentials of constitutional democracy - let us call this 'negative reasonableness', ${ }^{51}$ and b) reasonableness can be defined positively, in which case doctrines are reasonable because they actually share the vision ${ }^{52}$ of political liberalism, not just not contradict it - let us call this 'positive' reasonableness.

But at the second level of justification Rawls requires an acceptance of liberalism for the right reasons, ${ }^{53}$ which excludes any interpretation of (a) as a sufficient condition of reasonableness; ${ }^{54}$ hence, one is compelled to adopt (b) as the necessary condition of reasonableness. Thus, in order to be classified as reasonable a comprehensive doctrine needs to positively accept several key conceptions that are part of political liberalism. Such conceptions include constitutional democracy, the fact of reasonable pluralism, the fact that differences among comprehensive doctrines are irresolvable, and the fact that politics must be based on the idea of reasonableness, not on the idea of $\operatorname{truth}^{55}$ - the list goes on and on. ${ }^{56}$ Even a cursory glance at these conditions makes it clear that although the claim is that political liberalism leaves 'philosophy as it is', it actually transforms comprehensive doctrines (or rather demands that they be transformed) in a way that is necessary to make them positively oriented towards it and harmonious with it (as against mere negative compatibility). ${ }^{57}$ If this is true, it would amount to a serious objection on the grounds that it contravenes its own professed goal of not interfering with comprehensive doctrines as long as they accept (a). ${ }^{58}$ Of course, certain comprehensive doctrines will find it easier to adopt Rawls' formulations than others, but there may still be number of otherwise 'reasonable ${ }^{59}$ comprehensive doctrines that will find it hard if not impossible to positively adopt Rawls' political liberalism.

The line of criticism introduced above becomes more clear and plausible when we consider a very revealing and enlightening example which is buried in a long footnote in 'The idea of public reason'. The note is revealing and interesting for several reasons. For one thing, the example is of a comprehensive doctrine that clearly falls outside the historical environment with which Rawls' political liberalism primarily deals: it treats Islam as a comprehensive doctrine and questions how it can be positively aligned with political liberalism. The example is also interesting because it comes from a set of comprehensive doctrines which, one would be naturally inclined to think, are hardly at all compatible with political liberalism, let alone positively aligned with it. The example of Islam is pertinent, however, as it brings into greater focus the reasons for the acceptance of political liberalism by a comprehensive doctrine in the first place. The example is also interesting because Muslims are increasingly becoming a sizeable segment of all developed constitutional democracies, and all demographic extrapolations point towards an increase in their numbers. Thus, Islam has already become an internal issue for political liberalism; it cannot merely be considered as an external concern. ${ }^{60}$

The second important reason why the note is significant is that Islam is, as Andrew March puts it, 'a 'comprehensive ethical doctrine' par excellence,,${ }^{61}$ hence of intrinsic interest for any theory, like the one of Rawls, built on a contrast between the notions of comprehensive doctrine and free-standing political conception.

Here I shall take Rawls' example, not (primarily) from the point of view of Islamic scholarship, but only for the sake of understanding Rawls' viewpoint. The note is attached 
to the answer ${ }^{62}$ Rawls gives to the question I quoted above, as to why a comprehensive doctrine would choose liberalism even in the face of its prospective decline. Rawls begins his note ${ }^{63}$ with the following words: 'An example of how a religion may do this (turn itself into a reasonable doctrine even at the expense of its possible decline) is the following' ${ }^{64}$ Rawls cites the work of Abdullahi Ahmed An-Na'im, who claims that superior Mecca teachings were rejected in favour of more practical Medina teachings, which were more viable in the historical conditions prevailing in seventh-century Arabia. ${ }^{65}$ Now the historical situation has changed, however, and it is possible to return to the Mecca period. But why? According to Rawls, 'An-Na'im believes that Muslims should follow the earlier Mecca period in interpreting Shari'a. So interpreted, he says that Shari'a supports constitutional democracy' ${ }^{66}$ It is here that Rawls quotes a key passage from An-Na'im:

The Qur'an does not mention constitutionalism, but human rational thinking and experience have shown that constitutionalism is necessary for realizing the just and good society prescribed by the Qur'an.

An Islamic justification and support for constitutionalism is important and relevant for Muslims. NonMuslims may have their own secular or other justifications. As long as all agreed on the principles and specific rules of constitutionalism, including complete equality and non-discrimination on grounds of gender or religion, each may have his or her own reasons for coming to that agreement. ${ }^{67}$

Rawls writes, commenting on the passage: 'This is a perfect example of overlapping consensus' ${ }^{68}$ If this is a perfect example of overlapping consensus, it should tell us a great deal about Rawls' political liberalism. I am not interested here in evaluating whether An-Na'im's interpretation is a plausible interpretation; ${ }^{69}$ what I am interested in is how this sheds light on Rawls' notion of comprehensive doctrines and its relation to political conceptions. Irrespective of whether one considers An-Na'im's interpretation as valid or not, there is no doubt that it proposes a wide-ranging transformation of Islam. ${ }^{70}$ In particular, the bulk of Islamic law belongs to the Medina period, and, more significantly, it was in Medina that the first Islamic state was established. So, what An-Na'im is advocating is Islam minus state and (at least) public law! An-Na'im's proposal to all practical purposes would amount to turning Islam into a private or confessional religion, one ultimately succumbing to the parameters of a modern state in principle and not on just a pragmatic basis. ${ }^{71}$

I do not intend to question whether such a transformation is possible; it may very well be possible (and even desirable). After all, a very similar transformation took place in the case of Christendom. What I want to emphasise, however, is that, whether possible or not, desirable or not, it is undeniable that such a proposal would require a huge transformation in the understanding and practice of Islam, a transformation parallel to the one that has happened in Christendom during the last four centuries or so. ${ }^{72}$ What the example makes clear is that political liberalism does not only limit comprehensive doctrines (if needed) - it totally reconfigures them. In the process of making Islam reasonable, Islam turns into something unrecognisable in historical terms. Political liberalism (constitutional democracy) turns out to be 'necessary for realising the just and good society prescribed by the Qur'an'. In this understanding, political liberalism is not content with merely appropriating ground for itself; it approaches the doctrines from behind and limits them, and this limitation at times involves drastic reconfiguration.

But if a political conception is as totalising as suggested by the interpretation above, then it turns out to be as comprehensive as comprehensive doctrines, if not more so. If this explanation is correct, Rawls' comprehensive doctrines (at least some of them) turn out not to be as comprehensive as they may seem; they need something beyond them to realise themselves. On the other hand, his political liberalism, in this interpretation, turns out to 
be more than just political. It is the conditions of the possibility of comprehensive doctrines that they realise their true essence and define their reasonableness. In this sense his liberalism is not very different from Habermas' theory of communicative action, the doctrine which Rawls says is comprehensive. ${ }^{73}$

To his credit, it must be admitted, Rawls correctly notes that 'For [An-Nai'm's] interpretation to be accepted by Muslims, it must be presented as the correct and superior interpretation of Shari'a, ${ }^{74}$ Again, I shall not contest here whether An-Nai'm's interpretation is a superior interpretation. ${ }^{75}$ However, note that, according to his own admission, An-Nai'm reinterprets the historical understanding of Islam and proposes a drastic new understanding, irrespective of whether or not it is a valid or even a better interpretation. He reinterprets the historical understanding of Islam just as he questions the understanding of Islam by the first generation of Muslims. According to his interpretation, until the advent of modern constitutional democracy superior Mecca teachings were neither realised nor realisable.

These seem to me pretty drastic claims and would require drastic reinterpretation of Islam (correct or otherwise). One of the great merits of Political Liberalism, and Rawls' subsequent writings, is its historical sensitivity. ${ }^{76}$ The argument Rawls develops in favour of the irreconcilability of many comprehensive doctrines intimately follows his understanding of religious wars and conflicts in the history of Europe and the West in general. He must realise that a parallel transformation of a comprehensive doctrine like Islam to a reasonable doctrine would inevitably require centuries of internal argumentation, if not warfare and internecine conflict, even if it were possible at all; surely he cannot assume that An-Nai'm's proposal could be instituted without comparable historical struggle.

If my assumption here is true, then it defeats the purpose of political liberalism. Recall that one of the main motives behind political liberalism, and its essential distinction between reasonable comprehensive doctrines and free-standing political conception, is, ceteris paribus, to minimise the conflict in political life and maximise its own plausibility. ${ }^{77}$ However, it would seem that in the case of one important comprehensive doctrine, (at least) one version of political liberal response ends up increasing conflict rather than decreasing it. Thus, at least for some comprehensive doctrines, certain versions of political liberalism might not present the best option - not even a better one. Hence, it would seem that at least in some cases political liberalism would need to join forces with other political positions to come up with optimal outcomes, or would need to revise some of its rigid requirements.

Since Rawls' main focus has been on the developed democracies of North America and Europe, where through a bloody historical process comprehensive doctrines have already evolved into reasonable doctrines, and where unreasonable comprehensive doctrines can be considered extinct or at least greatly weakened for all practical purposes, he tends to ignore the immensity of transformation and transfiguration required to turn a comprehensive doctrine into a reasonable one. Since a background consensus of the public political culture of democratic societies is presupposed by his theory ${ }^{78}$ he does not have any problem arguing for the possibility of building an overlapping consensus for political liberalism that does not refer to any specific comprehensive doctrines (except for a reference to the shared values that they enjoy). But this gives a false impression about the thinness of political liberalism. If one takes into account not just the given background consensus, but the whole history that is invested in putting this consensus into place (often a very bloody and painful history), one realises that political liberalism is more than it claims to be; when we realise this, a powerful and - to an extent - rather totalising spectre emerges, which requires all comprehensive 
doctrines to reconfigure themselves according to its particular vision. ${ }^{79}$ Then, naturally, the appeal of political liberalism as a 'neutral' and 'non-interfering' arbitrator is greatly diminished. Similarly, given the enormity of the transformation required in certain cases, ${ }^{80}$ it seems only logical that different levels of irreconcilability be attributed to comprehensive doctrines before they are reasonable and after they have become reasonable, which will, at least, obviously diminish the urgency of the political liberal solution. This is the dual point which has come to the fore in our discussion, and at least brings forth a significant tension in Rawls' core argument for political liberalism.

In this context I would like to single out the second level of justification, in which political liberalism requires citizens to embed principles of political liberalism within their own respective comprehensive doctrines. On the face of it, this must be done so that any liberal comprehensive doctrine, as opposed to political liberalism, is not imposed on citizens holding different comprehensive doctrines than liberalism. ${ }^{81}$ However, paradoxically, this strategy may end up doing exactly what political liberalism wants to avoid, or even worse. The example of Islam makes clear that a Muslim citizen of a liberal state, in Rawls' conception, when required to embed liberal conceptions into her own comprehensive doctrine, may need to indulge in a massive reinterpretation of Islam. It is true that Rawls wants this reinterpretation to come from within Islamic principles and by Muslims, but irrespective of whether it comes from within or without, as noted above, it would in all possibility initiate an unending debate about its legitimacy and practicality, among other things. Moreover, all indicators are that the dominant perception would be that the pressure to do this comes from liberalism and not from within Islam. That is the practical reality. ${ }^{82}$ Due to this perceived interference, Islam as a comprehensive doctrine might drift even farther from its rapprochement with liberalism. Thus, the good intentions at the second level of justification may end up making things worse. ${ }^{83}$

One can even claim on more general grounds that the second level of justification is inherently interventionist, or that it becomes interventionist, at least, when it is deemed a necessary condition for all citizens and all comprehensive doctrines. It is interventionist in that it asks the members of comprehensive doctrines to embed political liberalism within their own doctrine (or, more value-neutrally, to justify political liberalism based on their own internal reasons). It is an interventionist strategy, as it puts pressure on comprehensive doctrines from outside to do something which is not necessarily required by the logic of the doctrines itself. It is interventionist in that it may initiate unnecessary schisms and divisive debates within the doctrines. It might be claimed that religious wars and conflicts of the past have taught all reasonable doctrines that it is impossible to have a political system based on a single comprehensive doctrine without using an immense amount of oppression. Even if one accepts this objection, which might be reasonably doubted by some, two caveats remain: a) not all comprehensive doctrines would necessarily interpret the religious wars in the same way and draw the same lessons from $\mathrm{it}^{84}{ }^{84}$ and $\mathrm{b}$ ) even if all doctrines draw the same conclusions and the same lessons from the religious wars of the past, this does not imply that they will necessarily agree with the positive prescriptions of political liberalism.

In fact, there is a much deeper paradox inherent within the very idea of the second level of justification, if seen within the context of Rawls' overall argument, and the paradox is an extension of the paradox within the overall argument. I will explain this by claiming that there are two facets of liberalism; let us call them 'independence' and 'dependence' facets. I will first lay down the main elements of these two facets and then formulate the paradox that is created by the tension between them. 


\subsection{Independence}

Political liberalism is a free-standing conception in the sense that it is conceived as an abstraction from all the comprehensive or partially comprehensive doctrines; no reference is made to these doctrines in the formulation of the political conception, and it is formulated as a complete conception as far as the political realm is concerned: '[political liberalism] works entirely within [the] domain [of the political] and does not rely on anything outside it ${ }^{85}$ Moreover, the justification of the political conception in the first instance is - crucially - pro tanto; at this stage the political conception is justified on its own terms without any reference to comprehensive doctrines.

At the second level of justification every citizen justifies and embeds the political conception (privately) with reference to her own respective comprehensive doctrine. Again, very crucially, this is done in abstraction from the political conception and without any reference to or interference from it (hence total independence from the political conception in this case).

\subsection{Dependence}

The deepest convictions of the citizens (and their identities) are formed by and within comprehensive doctrines. ${ }^{86}$

The full justification of the political conception by citizens and the embedding of it into their respective comprehensive doctrines are absolutely crucial for Rawls for three interrelated reasons.

a) The ability of citizens to be able to embed and justify the political conception is important for the independent character of the political conception because without this the very rationale for the independence collapses.

b) The ability of citizens to embed and justify the political conception within their respective comprehensive doctrine is also absolutely crucial for the distinction between the overlapping consensus and consensus for the wrong reasons, and consequently for stability for the right reasons. The social unity founded on Rawls' political liberalism 'is the deepest because the fundamental ideas of the political conception are endorsed by the reasonable comprehensive doctrines, and these doctrines represent what citizens regard as their deepest convictions, religious, philosophical, and moral'. ${ }^{87}$

c) Full justification is the necessary condition for public justification (justification at level 3), which in turn is absolutely crucial for stability for the right reasons as well as for the liberal conception of legitimacy discussed earlier. ${ }^{88}$

It is not only dependent on comprehensive doctrines for its full justification, but also for checking whether it is in fact a reasonable political conception, because it is only when individual citizens are able to form an overlapping consensus about the political conception that it is sufficiently assured and checked so that it 'can be sincerely defended before others without criticizing or rejecting their deepest religious and philosophical commitments ${ }^{9}{ }^{99}$

\subsection{Paradox}

Combining $2.1 \& 2.2$ we get these two paradoxical results:

a) Although the intention is to stay independent of comprehensive doctrines, the political conception is in fact totally (and precariously) dependent on comprehensive doctrines (not just on one doctrine but on each and every major doctrine in the society).

b) The very search for independence makes the political conception more dependent on comprehensive doctrines, and by extension makes it potentially more susceptible to 
intervention in and tempering by comprehensive doctrines (it is enough to show that it is a strong conceptual possibility to cast doubt on the whole strategy).

Is Rawls' argument doomed, then? I think that despite the serious problems demonstrated in the above discussion the argument may be revised in a way that at least makes it less self-contradictory. The trick is to make it more flexible. A comprehensive doctrine (for example) might accept political liberalism on the basis of a modus vivendi in a way that might not be far off the overall spirit of political liberalism. If the inner logic of liberalism demands avoiding needless controversies, maximising its plausibility ${ }^{90}$ for other doctrines, then it should be more flexible in its strategy.

In the next section I shall suggest what I believe to be key elements of such a flexible strategy, although, given space constraints, I shall leave the full elaboration of such a strategy for another occasion.

\section{A REVERSE CONJECTURE}

Rawls is right to insist that political liberalism be justified and adopted for the right reasons in order to fulfil the condition of stability, but he is wrong to insist that all citizens must support a liberal political conception for the right reasons. ${ }^{91}$ More crucially, he is wrong to insist that all citizens must partake in the second level of justification. The condition of stability is met when a critical mass of people and doctrines adopts liberalism for the right reasons, and does not necessarily require all reasonable ${ }^{92}$ comprehensive $^{2}$ doctrines to support a system for the right reasons. There is thus no need for all citizens and all reasonable comprehensive doctrines to accept political liberalism for the right reasons and to partake in the second level or full justification. ${ }^{93}$ It is sufficient if they accept political liberalism for pragmatic reasons (of various kinds). ${ }^{94}$

I envisage here two different kinds of justification. The majority of citizens and the majority of reasonable comprehensive doctrines would accept political liberalism for the right reasons and partake in full justification (which would provide the system with enough resources for stability). A sizeable minority of citizens would accept political liberalism for different pragmatic reasons, and there would be some comprehensive doctrines which might not partake in the full justification at all (at least not in the way envisaged by Rawls; more on this below). This exemption should not threaten the stability of the system, however. All human systems must partake in the human fate of minimum fallibility and uncertainty. ${ }^{95}$ Moreover, there would be others - hopefully not too many ${ }^{96}$ - who would reject the system, so there would be some pockets of comprehensive doctrines which would be regarded as unreasonable. They would be left alone as long as they did not violate the law. It should be noted that this exclusion is normal, as no system can positively tolerate doctrines that are incompatible with it or which actively undermine the system.

Now liberals (especially Rawlsian liberals) have insisted that justification should be for the right reasons, and have interpreted this as justification on moral grounds, contrasting it with pragmatic justification. I shall briefly argue that justification on moral grounds does not necessarily exclude a pragmatic justification. It is obvious that any comprehensive doctrine living within a liberal regime would have to take a position vis-à-vis political liberalism. This justification would be internal, as Rawls grants. However, one can understand 'internal' in two distinct and not necessarily mutually exclusive ways. Internal justification can take the form Rawls envisages for it under level 2, where a comprehensive 
doctrine justifies political liberalism for its own internal reasons. However, one can think of another possible sense of internal justification whereby a doctrine does not necessarily justify political liberalism as such, but describes how to deal with it, given that it exits. ${ }^{97} \mathrm{In}$ such a case, a comprehensive doctrine might ask, given that the cultural dominance of constitutional democracy (Rawls assumes) and kindred conceptions (and doctrines) are facts of life, what are the guidelines for dealing with it and living under it? The answer may follow from internal reasons and principles.

The latter variety of internal justification is justification not of liberalism as a conception, but of life under such a conception as an existential fact. Of course, such a justification is not ideal from a liberal viewpoint (and not sufficient for the stability of the system; thus we require that most doctrines justify liberalism and not just deal with it), but such a justification is not ideal for a comprehensive doctrine either. Given that no comprehensive doctrine can assume itself to be in charge all the time, every comprehensive doctrine must have a strategy in order to offer guidance in a situation when it is not in charge. Such a justification for dealing with liberalism can be both moral and pragmatic at the same time. It can be pragmatic in the sense that it is not necessarily a justification of a doctrine or conception but a justification for living or even participating under it. Different doctrines can justify the same system and the same activity for different reasons. They can support political liberalism either in terms of justifying its core ideas or dealing with and participating in it, or both. According to moral pragmatic justification a comprehensive doctrine justifies living under liberalism or participating within it without necessarily justifying its core principles, and does this not on purely strategic or existential grounds but on the grounds of its own moral principles or teachings on how to deal with or live under alien systems when required.$^{98}$ Such a moral, pragmatic justification must be distinguished from a mere pragmatic justification whereby a doctrine justifies liberalism or dealing with it out of pure necessity or even as an opportunistic move. A sincere, pious Muslim citizen of a liberal state, for example, would not justify living under liberalism (it might be that, doctrinally speaking, she cannot even consider it desirable) from a purely opportunistic point of view; she will base her justification on the moral guidance of Islam regarding how to live within alien systems when required or through necessity. Thus, a pragmatic justification does not necessarily exclude justification on moral grounds.

A liberal might say at this point that: a) liberalism must be justified and not just dealt with; and b) liberalism itself must define what counts as the moral justification for liberalism. ${ }^{99}$ But these conditions would be against the inner logic of liberalism itself. Unless it is shown that such an approach is necessary for some other reasons, it cannot be defended on the basis of liberalism's inner logic, which demands, other things being equal, the maximising of its plausibility and the minimising of unnecessary conflicts. A liberal may argue that these are required by the imperative of stability. This is, as we have noted, a genuine concern. But unless it is shown that stability requires all citizens and all comprehensive doctrines to justify liberalism to the same degree, the argument fails. ${ }^{100}$

While it is not possible to investigate the issue here, intuitively speaking it seems plausible that most systems can happily live with a strategy that mixes full justification with all sorts of secondary levels of justification. As mentioned before, according to the scenario I envisage a large majority will justify the liberal conception as well as live with it according to the full justification model presented by Rawls. However, there would be sizeable minorities who will either justify the liberal conception or live under it, or both, either on a pragmatic moral basis or merely on a pragmatic basis. Moreover, there might be doctrines that do not accord with it. Such a scenario seems intuitively closer to the 
actuality ${ }^{101}$ and coheres with the inner logic of liberalism without compromising its stability. ${ }^{102}$

In order to institute the multi-tiered and multi-layered system of justification proposed above, we need to make certain amendments to Rawls' account. The main amendment would be to expand the definition of the reasonableness of comprehensive doctrines and to make the second level of justification optional. We will now define reasonable comprehensive doctrines as those doctrines that are not incompatible with the essentials of constitutional democracy, or ones which may be incompatible with the essentials of constitutional democracy but are able to accept constitutional democracy on pragmatic/ moral, pragmatic, or even merely existential grounds. Habermas realises this when he make his crucial distinction between fundamentalism and orthodoxy: ' $\ldots$ orthodoxy only becomes fundamentalist when the guardians and representatives of the true faith ignore the epistemic situation of a pluralistic society and insist - even to the point of violence - on the universal validity and political imposition of their doctrine'. ${ }^{103}$ In Rawlsian terms, a doctrine that renounces violence, ${ }^{104}$ does not aim to impose its doctrine politically (at least not in practical terms) and accepts constitutional democracy on practical/moral or even merely practical grounds, should be classified as a reasonable doctrine (contra Habermas, adherents of such reasonable doctrines would be free to claim universal validity for their doctrines as long as they did not resort to violence; political liberalism is not in the business of stopping people from making claims!)

What is required is a minimalist definition of reasonableness; alternatively, we can differentiate between two senses of reasonableness: strong and weak. We would have a majority or near majority of doctrines that might be classified as reasonable in the strong sense, but this would still leave room for doctrines that are reasonable in a weak sense. These can in turn be graded on the level of support they give to liberalism. Such a minimalist definition of reasonableness would attract similar objections to the one outlined above in the context of moral versus pragmatic justification. Similarly, I propose that justification at the second level be made optional. It is expected (and desirable from a liberal viewpoint) that most doctrines embed liberalism in their own doctrines and defend it in positive terms. However, making such a step necessarily would amount to interfering (and putting pressure on a doctrine) from outside, which does not sit well with the noninterfering spirit of liberalism as discussed above. ${ }^{105}$

Doubtless one can come up with many objections to these proposed amendments from a liberal point of view. I shall consider the more important of these below, to show how they can be dealt with. One can say that granting exceptions to certain minorities from the full-blown justification can make those minorities permanently suspect in the eyes of the majority. A possible reply to this might be that there is no guarantee that those very same minorities would be spared the gaze of suspicion even if they partook in the full justification. History attests to this. Catholics, for example, remained an object of suspicion in America, Britain and elsewhere, for a long time, despite sharing language, culture and much more with the majority culture, because of the suspicion that their loyalties were divided. This was despite numerous concessions to the system from Catholics who adjusted their position to conform to the dominant political milieu. Humans are prone to such silly prejudices; one can hope to overcome some of that silliness, but the hope of transcending it entirely is faint, to say the least. One has to learn to live with human weaknesses; this is the lesson of political liberalism.

Another objection that might be raised is that if certain segments of populations are granted a space to thrive within the system (by providing them with a sort of legitimacy 
that is lacking in the case of unreasonable comprehensive doctrines), in the long run they might be in a strong position to undermine the system. To this one could reply that this is not a necessary contingency; granting them space can also provide an opportunity to assimilate them into the system, by education, etc, if not in the first generation, then in all likelihood in the second and third generations, when they will be willing to partake in the full-blown justification. If this does not transpire, then one would have to live with it. A system should primarily rely on its own strengths rather than becoming totally absorbed in continuously fool-proofing itself against the slightest possible or imaginary dangers. No system can make itself invincible. ${ }^{106}$ No system (including political liberalism) is here to stay forever, although certain trends in political liberalism smack of this desire to make a system based on liberal values invincible.

Andrew March puts this sentiment well when he writes: 'Demonstrating the stability of an overlapping consensus requires demonstrating that those supporting liberal institutions as a minority would continue to support them as a majority'. ${ }^{107}$ Now, if the idea is that a group might support liberal institutions as a minority, but then choose to run roughshod over other minorities if they ever became the majority, then one might say that this would be a possible worry for the stability of any liberal institutions that had no built-in guarantees of minority rights. But most democratic theorists, from Mill to Rawls, built (constitutional) guarantees of minority rights into their conception of liberal institutions. So, for those theorists, it is not clear what the problem would be. One could say that the group that became the majority might somehow choose to abolish the liberal institutions or the guarantees of minority rights, but this does not seem to be very feasible ${ }^{108}$ in practice if the liberal institutions were already well-entrenched. In addition, even if this were a worry, it would be so even when you had no majority at all but only an overlapping consensus of minorities - in theory you could have various minority groups agree to 'gang up on' and persecute one particular minority (e.g., Jews, or gays, or Muslims). And if that is not a worry when you have an overlapping consensus of minorities, then it is not clear why it would suddenly become a worry if/when one of the minorities became a majority.

If, on the other hand, the idea is actually to foreclose the revolution, then one should distinguish between a theoretical concern for de-legitimizing revolution and a practical desire to foreclose any possibility of a revolution. The issues about de-legitimizing revolutions designed to overturn liberal institutions are not the same as those concerning the feasibility of such revolutions and of the de facto stability of liberal institutions. If liberal institutions with guarantees of minority rights are an ongoing, entrenched form of government, then revolutions to overturn them may not be very feasible, irrespective of the legitimacy of such attempted revolutions. In addition, it seems that some liberals may think, as Rawls at times seems to think, that a political system can only be stable if it can somehow be shown to be impossible to overturn. ${ }^{109}$ This seems like a ridiculously rigid conception of stability. Surely you can regard a political system as very robust and stable while granting that it may not last forever or suggesting that there may be no way of guaranteeing that it cannot be overthrown or replaced, in which case it seems obvious that no political system is or could be stable, and so the matter hardly seems worth discussing or debating.

None of the elements of stability noted by researchers in the field require a system to be unrealistically shock-proof. Steve Ove Hansson and Gert Helgesson note the following three elements of stability in the literature: a) constancy; b) robustness; and c) resilience. The ability to withstand revolutionary changes pertains to the property of robustness, and a 'political system is stable if it can withstand reasonably substantial shocks'. ${ }^{110}$ This seems 
reasonable, and Rawls has every right to hope for such robustness for his proposed arrangement. However, to claim that this should include sealing the possibility of revolution is to go beyond such reasonableness. It is part of the notion of feasibility that a conception be internally coherent. It is part of the stability of a conception (even of stability for the right reasons) that it be realistically plausible (conceptually speaking and not just merely empirically). If the conditions of stability for the right reasons are not presented in realistically plausible terms, this weakens the idea itself. So, it is unrealistic to propose a notion of stability which harbours unrealistic goals. There is nothing pragmatic (in a wrong way) about it.

\section{CONCLUDING REMARKS}

In this paper I have discussed two distinct but interrelated issues. I have first argued that Rawls' argument for political liberalism contains critical tensions and paradoxes that make his overall thesis less persuasive. In the second part I have argued that the tensions within political liberalism can be overcome, or at least made tolerable, by making it flexible. In both parts my intention has been exploratory rather than exhaustive, although I have examined the inconsistencies within the theory of political liberalism in greater depth than the discussion on how to make the argument flexible, where I have put forward an argument quite literally indicative and programmatic.

The argument of the first part is internal in that it aims to evaluate liberalism and its inherent tensions from within political liberalism itself, although I do not claim to be a supporter of political liberalism as such. I have great respect for Rawls as a philosopher, and I have treated his argument seriously whilst - naturally - maintaining an ironic distance from it. In proposing required changes in part two, my stance is more ironic than in the first part, partly because here I am engaged in two slightly different acts: proposing certain amendments and certain practical proposals in the spirit of charity in order to overcome logical tensions and paradoxes that emerge; nevertheless, here I am also engaged in a conjecture which is more ironic in spirit than a purely internal position would allow. Hence in the second part my position is simultaneously internal as well as external. The conjecture is reverse in the sense that it tries to test the magnanimity, tolerance, and mutuality preached by political liberalism. It is also a reverse conjecture in the sense that it is demanded from a position outside the liberal conjecture itself (although I have intentionally refrained from naming it, partly because I do not really know what my own position is, but also because I am aiming to speak from all non-liberal positions, as far as one can talk about such a general position). Political liberalism rejoices in putting other doctrines on trial; it is only fair that it tastes its own medicine from time to time. This is in line with Habermas' insistence that political liberalism as it stands is monological, and that it should be more dialogical in a genuine sense; this will involve facing and testing the limits of the proposal from the ironic distance of the other. ${ }^{111}$

There are two things which became clear to me only once I was finished with writing this paper, and I present them here as matters for further investigation. It seems to me that Rawls' position was much more flexible in the original presentation of Political Liberalism and has gone in the direction of stringency in his subsequent writings, aimed at clarification and replying to objections. ${ }^{112}$ Rawls was right in taking seriously the problem of clearly distinguishing his methodology from a modus vivendi approach understood as pragmatic compromise or a balance of power or reasons. But as I have shown in this 
paper, there is no need to forgo the flexibility of political liberalism in order to achieve this aim. I would suggest that, all things being equal, flexibility is the main charm of Rawls' political liberalism, and if he does away with flexibility in favour of a more stringent position the very rationale of the move from A Theory of Justice to Political Liberalism becomes hard to sustain.

The second, and much more important, issue is the omission of a discussion on immigration. As is well known, in Political Liberalism Rawls treats society as a closed system which individuals enter on birth and exit only on death. ${ }^{113}$ This is a methodological step and an abstraction to which Rawls is entitled in principle. Accordingly, Rawls leaves out the discussion of immigration in developing his political liberalism for a modern society defined by liberal nationalism and a fairly strict regime of border controls, amongst other things. ${ }^{114}$ This would have created a plausible picture of a modern liberal society but for two facts about such societies that Rawls entirely omits. The first is the fact of globalisation, which has rendered the movement of ideas and cultural differences, if not the people themselves, beyond the restrictions of national boundaries. Second, and most importantly, almost all modern democratic societies which are in the background in Rawls' conceptualisation of political liberalism have been greatly transformed by the fact of immigration (and this transformation is an on-going fact of life in these democracies). The fact of immigration has tilted the balance of the original population of societies, and has introduced unforeseen cultural, ideological, and philosophical trends in the equation which did not exist before. Combine this with the additional fact of shrinking population growth in first-world societies, and it drastically changes the whole scenario on which Rawls' conception of political liberalism is based. Recall that Rawls, to support his argument, assumes the background public political culture of democratic societies. But he can only do so, however, if he assumes that the facts of immigration and globalisation are not going to affect (if they have not already) the public culture of constitutional democracies in any fundamental way. Even if the assumption is realistic it should be addressed explicitly for the viability of the argument. True, Rawls' argument is not empirical, but as I have argued in this paper, the coherence of the conception depends also on the fact that the scenario it envisages and the conditions it puts forth are realistically plausible. Hence, if the model is too much at variance with the ground conditions, then it becomes suspect as a realistic option regardless of whether the argument is empirical or merely conceptual.

\section{Notes}

1 I have discussed the issues involved in this paper with my friend John Campbell over the years, and his comments and feedback have been invaluable. Jeremy Lowe, Aynur, and an anonymous referee for this journal provided valuable comments and suggestions, which have greatly improved this paper. I am grateful to them all.

2 John Rawls, A Theory of Justice. Rev. edn (Cambridge, MA: Belknap, 1999).

3 John Rawls, Political Liberalism. Rev. edn (New York: Columbia University Press, 1996).

4 For an excellent account of the transition from $A$ Theory of Justice to Political Liberalism and how to understand it, see Thomas E. Hill, Jr; 'The Stability Problem in Political Liberalism', in his Respect, Pluralism, and Justice: Kantian Perspectives (Oxford: Oxford University Press, 2000), pp. 237-259; also see Burton Dreben 'On Rawls and Political Liberalism', in Samuel Freeman (ed.) The Cambridge Companion to Rawls (Cambridge: Cambridge University Press, 2003), pp. 316-345.

5 There are a total of six facts, the details of which are set out in Rawls, Political, pp. 35-40 and 58.

6 Rawls, Political, p. 37. Hence the contradiction inherent in Rawls' position as presented in A Theory of Justice, as it is based on a comprehensive moral (Kantian) doctrine on one hand, but on the other hand, it promotes as a core value maximum freedom for each and every individual compatible with similar freedom for everyone else, which generates pluralism. 
7 The fact of oppression and reasonable pluralism are the facts of free reason itself: Rawls, Political p. 37.

8 Thus Rawls' later position emerges out of the contradiction within his position set out in $A$ Theory of Justice itself. The contradiction is succinctly described by Rawls in his 'Political Liberalism: Reply to Habermas', The Journal of Philosophy 92, 3 (1995), pp. 132-180 (here pp. 145ff.); also see the works of Hill and Dreben referred to above.

9 I am not claiming here that Rawls' position in Political is value-neutral or minimal; what I am claiming is that there is an element of neutrality and minimalism in his later approach which is to be understood from within the position itself. Thus there are right and wrong conceptions of neutrality: the right conception of neutrality emanates from and is embedded within a principled position while the wrong conception of neutrality is a mere modus vivendi; the same is true for minimalism and other related notions. Political liberalism is neutral and minimal in the sense that it eliminates 'any idea which goes beyond the political and which not all reasonable comprehensive doctrines could reasonably be expected to endorse' (Rawls, 'Reply to Habermas', p. 145, also see ibid., p. 134). But this is done for the right reasons in the sense that it is the demand of the liberal political conception itself; infringing it will infringe the principle of mutuality which is the core liberal principle (ibid., p. 145). Liberalism is also neutral and minimal in the sense that it is free standing; we do not rely on anything outside it to formulate it (ibid., pp. $133 \& 145$ ). It is presented as independent from every doctrine, but the hope is that it can be supported by everyone (Rawls, Political, pp. 134-135). But liberalism is not neutral or minimal in the sense of being value-neutral. In the lingua of feasibility theorists, for Rawls the feasibility approach is part and parcel of the desirability approach, but on the condition that feasibility is understood in the specific (normative) sense Rawls gives it. The feasibility of a theory, i.e., that it should be in principle acceptable to all reasonable persons, is the question of principles for Rawls because of the way he sets his problem. Thus if a theory is not feasible in the Rawlsian sense it will infringe upon the core principles on which his theory is based (i.e., the legitimacy principle [criterion] of liberalism). On the distinction between the desirability approach and the feasibility approach, see an excellent paper by Juha Räikkä, 'The Feasibility Condition of Political Theory', The Journal of Political Philosophy 6 (1998), pp. 27-40.

10 Rawls, 'Reply to Habermas', p. 140 n. 13.

11 But see the proviso noted by John Rawls, 'The Idea of Public Reason Revisited', Chicago Law Review 64 (1997), pp. 765-807 (here p. 776).

12 By 'liberal' I mean here liberalism as a comprehensive doctrine and not a political conception.

13 At times Rawls treats overlapping consensus as a fact about the culture of constitutional democracies. See Rawls, 'Reply to Habermas', p. 144 n. 20, in which case the whole purpose of the three-tiered justification would be in part to make explicit what is implicit.

14 Rawls' discussion of how to do this is couched in terms of 'conjecture' (See Rawls, 'The Idea of Public Reason', pp. 786-787). The key points Rawls notes is that conjecture must be sincere and non-manipulative, and the purpose of conjecture is not just to show the Other how they might accept political liberalism from within their respective comprehensive doctrines but also to clarify the Other's and our own misunderstandings about each other. On this point, also see Andrew March's illuminating and perceptive comments in 'Islamic Foundations for a Social Contract in Non-Muslim Liberal Democracies', American Political Review 101, 2 (2007), pp. 235-252 (here pp. 237-238). Rawls sometimes also describes formulations related to the original position as conjectures (see Rawls, 'Reply to Habermas', p. 139.)

15 Consensus involves balance of reasons from within each and every comprehensive doctrine as seen by its members and not a compromise compelled by circumstances (Rawls, Political, p. 169).

16 Rawls talks about 'the practical task of containing them' as they are 'war and disease' (Rawls, Political, p. 64 n. 19; also p. 64ff.). But one does not just contain diseases, one tries to eradicate them!

17 Rawls, Political, pp. xxvi \& 13.

18 Although it is correct that Rawls' argument deals with the logical (conceptual) possibility and logical plausibility of political liberalism (including its internal coherence) and is not an argument for its empirical feasibility, nonetheless the argument should not be construed as intended to show the mere logical possibility of the political conception (for the distinction between logical possibility and mere logical possibility, see hints in John Rawls, The Law of Peoples; With 'the Idea of Public Reason Revisited' (Cambridge, MA: Harvard University Press, 1999), p. 128). I agree here with James Bohman and Henry S. Richardson that what Rawls needs to show is that his solution is a 'realistically plausible outcome, not....merely a possible one' ('Liberalism, Deliberative Democracy, and 'Reasons That All Can Accept', The Journal of Political Philosophy, 17 (2009), pp. 253-274 (here p. 15). David Copp also makes the same distinction in terms of a distinction between 'mere logical possibility' and "real' possibility' and explains the latter in terms of the 'idea ... that there is a real possibility of an overlapping consensus if causal mechanism in the real world could produce a consensus.' (David Copp, 'Pluralism and Stability in Liberal Theory', The Journal of Political Philosophy 4 (1996), pp. 191-206 (here p. 200). Copp further defines 'real' possibility as showing possibility of a non-adventitious consensus (pp. 200-201).

19 That is what makes political liberalism reasonable. I agree with Bohman and Richardson that any viable conception of reasonableness (in this context) must be normative ('Liberalism', p. 15ff.) As we shall see, what makes it normative is the mutuality principle.

20 Rawls states the liberal principle of legitimacy as follows: 'our exercise of political power is fully proper only when it is exercised in accordance with a constitution the essential of which all citizens as free and equal may reasonably be expected to endorse in the light of principles and ideals acceptable to their common human reasons' (Rawls, Political, p. 137). 
21 The democratic liberal regime is to be supported unconditionally, Rawls, 'The Idea of Public Reason', p. 782, not in the sense of unquestionable loyalty but of non-instrumental, non-pragmatic loyalty. Also see ibid., p. 781, where the phrase 'firm allegiance' is used.

22 As Rawls notes repeatedly, political liberalism is not a political compromise. See, for e.g., Political, p. 171; also see on this the stimulating paper by Larry Krasnoff, 'Stability and Normitivity in Rawls' Political Liberalism', The Journal of Philosophy 95, 6 (June 1998), pp. 269-292.

23 In the discussion below, unless otherwise stated, by a liberal regime I always mean a political liberal regime and not a comprehensive liberal regime.

24 But note here that, according to Rawls, the roots of loyalty lie within comprehensive doctrines: Rawls, 'The Idea of Public Reason', pp. 784-785. This will be important for my argument as it develops.

25 For a succinct account of the three levels of justification in Rawls and their relation to the conception of legitimacy and stability for the right reasons see Rawls, 'Reply to Habermas', pp. 142-149.

26 At the third level of justification (public justification) citizens become aware of (and take into account) the fact of the existence of an overlapping consensus, but, crucially, they do not look into the content of individual doctrines (which would be practically impossible and normatively undesirable as far as the purpose of justification is concerned).

27 Here essential pragmatism occurs in the calculation of the members of comprehensive doctrines, and Rawls needs to show that such pragmatism is compatible with the justification of liberal political conception for the right reasons. I think he can only do that if he either shows or presupposes that the core liberal political ideals regarding constitutional democracy are not only espoused by all reasonable comprehensive doctrines (which is almost included in the definition of the reasonable), but also (and this cannot possibly be included in the definition of the reasonable except at the charge of circularity) that their acceptance of the liberal principles outweigh their allegiance to the defining tenants which constitute the core identity of their views (see Rawls, 'Reply to Habermas', pp. 146ff.)

28 Rawls, 'Reply to Habermas', p. 149.

29 'Yet our religion may enjoin many things. It may require our support of constitutional government as that which, of all feasible regimes, is most in accord with the religious injunction to be equally concerned with the basic rights and fundamental interests of others as our own'. 'Reply to Habermas', p. 149). But Rawls' reasoning here is sound only if its (i.e., religion's) support of constitutional government outweighs its support of all other values, including the values which define a religion's core identity.

30 By 'grave' we can reasonably mean any contravention that affects the core of a comprehensive doctrine or the core of the political conception.

31 Rawls, 'Reply to Habermas', p. 147. But this may in turn contradict Rawls' claim elsewhere that non-political values are essential to citizens and his similar comments about the relative unimportance of politics (in this context also see n. 29 on the same page and Rawls, Political, p. 157). I will come back to this possible tension below.

32 Such differentiation is needed for any regime but is especially critical for a liberal regime for the reasons mentioned above.

33 As March notes, 'the only principle to which the outside conjecture [i.e., the liberal conjecture] is absolutely committed is that of plausibility'. 'Islamic Foundations', p. 239.

34 Rawls, 'The Idea of Public Reason', p. 781, emphasis added.

35 Ibid., p. 782.

36 Rawls, Political, p. xli.

37 ' $[\mathrm{T}]$ he distinction between a political conception of justice and other moral conceptions is a matter of scope: that is, the range of subjects to which a conception applies and the content a wider range requires'. Rawls, Political, p. 13; more on this below.

38 Here I am somewhat conflating generality and comprehensiveness. For more details see ibid., p. 13.

39 Rawls, 'The Idea of Public Reason', p. 782.

40 Rawls, in 'The Idea of Public Reason', p. 778, supports this interpretation, where it is claimed that notions of moral autonomy fail to satisfy a condition of reciprocity because citizens holding religious doctrines may (reasonably) reject it.

41 Avoidance strategy: ' . . . a political conception tries to avoid, so far as possible, disputed philosophical theses and to give an account of the burdens of reasons that rests on plain facts open to all'. Rawls, Political, p. 57 n. 10 ; also see ibid., p. 152.

42 Rawls, 'Reply to Habermas', p. 148.

43 Rawls, Political, p. 157.

44 Rawls' position here lends itself to two possible interpretations. In the first interpretation, Rawls can be read as saying that since (a), (b) \& (c) are sufficient reasons, any doctrines which reject them are unreasonable, in which case the question would be entirely logical, but one would wonder about the reasonableness of such solution even by political liberalism's own light. In the second interpretation, Rawls seems to be saying that since (a), (b) \& (c) are reasonable conditions (and since they are sufficient conditions as well), it is reasonable to expect of a doctrine that it accept the liberal solution even at the peril of its own decline.

45 This is just one example of possible core values which can never be compromised.

46 Political liberals believe that 'the concern for salvation does not require anything incompatible with [] liberty' (Rawls, Political, p. 153), but this is just a hope or belief, and no more!

47 In his short but very interesting biographical piece on Burton Dreben, Rawls writes (referring to Dreben) something that might obliquely reveal an anti-salvationist streak in Rawls: 'Though Burt considers Wittgenstein 
one of the greatest philosophers, he thinks that he also was not a great or even a good man. Burt believes that his moral and religious ideas, his concern with his guilt and personal salvation, were indeed rather childish, and that Wittgenstein didn't know and didn't understand the religion of the prophets. What counted for them was the order of righteousness, justice, and humanity in the public world of the people and in their customs and practices of life. Sacrifices, prayers and hymns cannot substitute for these [Rawls refers here to Isaiah 58]. Lincoln was not a philosopher, but Burt would say he was a great man ... Lincoln understood the religion of the prophets, as the Second Inaugural makes clear, and Burt has said that a grove of oaks would have been a better memorial to Lincoln than the classical temple he was to have'. [John Rawls 'Afterward: A Reminiscence', in Juliet Floyd (ed.) Future Pasts: The Analytic Tradition in Twentieth-century Philosophy (Oxford: Oxford University Press, 2001), pp. 417-430 (here p. 423), emphasis added.

48 Rawls, Political, p. 4; Rawls, 'The Idea of Public Reason', p. 766.

49 Political values are lower values but still cannot be overridden by transcendent values; the doctrines in which political values are overridden are unreasonable; Rawls, 'The Idea of Public Reason', pp. 801-802.

50 See, for example, Rawls, 'Reply to Habermas', p. 134.

51 Such an account of reasonableness is ambiguously implied in Rawls, 'The Idea of Public Reason', p. 766, and more so in ibid., p. 807 and Rawls, Political, p. 169, for example.

52 But not necessarily reasons for supporting the vision.

53 On the second level of justification, citizens justify political liberalism with reference to their own doctrines as true or right and embed it within their doctrine. In public reason the ideas of right or truth are replaced by the reasonable. Hence political conception demands only that it be accepted reasonable; political conception need not to be accepted as true or right, nor does it claim to be (Rawls, 'The Idea of Public Reason', p. 798). And yet, political conception still must be confirmed by comprehensive doctrines (at the second level of justification) as true or right (ibid., p. 801, cf. Rawls, Political, pp. 126, 134 \& 151; Rawls, 'Reply to Habermas', p. 143).

54 Admittedly Rawls allows starting with a modus vivendi justification that will eventually lead to a principled acceptance of political liberalism (Rawls, Political, p. 159).

55 The idea that: ' $\ldots$ the whole truth in politics is incompatible with democratic citizenship and the idea of legitimate law' (Rawls, 'The Idea of Public Reason', p. 771).

56 Ibid., pp. 766-767, for example, where Rawls describes an acceptance of all these elements as the necessary conditions of the reasonableness of a doctrine.

57 Political conception would 'in fact ... have the capacity to shape those doctrines toward itself' (Rawls, 'Reply to Habermas', p. 145, Rawls, Political, pp. 158-168); also see Rawls, 'The Idea of Public Reason', p. 801). In other places, however, Rawls is more inclusive and more pragmatic and includes (a), (b) \& more; see, for example, Rawls, Political, p. 169.

58 Rawls, 'Reply to Habermas', p. 134.

59 This includes those doctrines which accept political liberalism only in the negative sense, as in condition (a) above, and also those doctrines which are reasonable in a more neutral sense of the term. Reasonable in this latter sense can mean various things: for example, renouncing violence in order to convert others, commitment to peaceful coexistence, etc. Rawls is quite explicit that political liberalism does not deal with those who reject constitutional democracy (Rawls, 'The Idea of Public Reason', pp. 766-767); however, the word 'rejection' in the quote is both ambiguous and vague - one needs to differentiate between those who reject constitutional democracy as their desired system and those who reject the option of living under it or dealing with it. Moreover, there is also a need to distinguish between those who actively reject constitutional democracy and those who only passively do so.

60 Andrew F. March has made this point forcefully in several of his recent writings; see, for example, 'Islamic Foundations', p. 236.

61 Ibid.

62 Rawls, 'The Idea of Public Reason', p. 782.

63 Ibid., n. 46.

64 Comments in parenthesis mine.

65 In Mecca Muslims were a small and persecuted minority. The Meccan teachings included mostly fundamentals of the Islamic faith (belief in the oneness of God, the Day of Judgment, etc,), the basics of Islamic worship and the fundamentals of morality. In Medina, Muslims were in the majority; Muhammad was the ruler and Islam was not only the law of the state he founded in Medina but the state itself. Naturally, Medina teachings included detailed guidelines relating to social and political matters (although matters of faith, worship and morality also continue to be discussed as well). Mainstream Muslims generally believe that Islam is the totality of both Mecca and Medina teachings and hence both a religion and a state. What An-Na'im is suggesting is to retain Islam as religion only. For a detailed account of both Mecca and Medina periods, see Alfred Guillaume, The Life of Muhammad: A Translation of Ibn Ishaq's Sirat Rasul Allah (Oxford: Oxford University Press, 1955). The best modern Muslim account in English is Martin Lings, Muhammad: His Life Based on the Earliest Sources (London: Islamic Texts Society and George Allen Unwin, 1986).

66 It would seem that it is constitutional democracy which is not limited by any historical situationist shortcomings; it is constitutional democracy which gives the Mecca period its presumed superiority.

67 Abdullahi Ahmed An Na'im, Toward an Islamic Reformation: Civil Liberties, Human Rights, and International Law, foreword by John O. Voll (Syracuse, N.Y.: Syracuse University Press, 1990), p. 100.

68 Rawls, 'The Idea of Public Reason', p. 783, n. 46, emphasis added. Note that for my argument here it is irrelevant whether An-Na'im's interpretation is correct or not; what is important is not An-Na'im's interpretation but the fact 
that Rawls sees it as a perfect example from the vantage point of his political liberalism. In this context also recall what Rawls says about the liberal conjecture: '[we] try to show them [i.e., the adherents of comprehensive doctrines] that, despite what they might think, they can still endorse a reasonable political conception that can provide a basis for public reasons' ('The Idea of Public Reason', p. 786, emphasis added).

69 It is interesting to note that a liberal scholar who has done extensive work on the possibility of an overlapping consensus between Islam and political liberalism almost totally (and consciously) ignores An- Na'im and his work for the reason of its implausibility in the context of Islamic tradition. See March, 'Islamic Foundations' and also his 'Liberal Citizenship and the Search for an Overlapping Consensus: The Case for Muslim minorities', Philosophy \& Public Affairs 34, 4 (2006), pp. 373-421, and Islam and Liberal Citizenship: The Search for an Overlapping Consensus (Oxford University Press, 2009).

70 In his introduction to An-Na'im's book, John O. Voll describes him as belonging to an 'unorthodox reformist' group and concedes that 'many Muslims will disagree with An-Na'im's views' (An-Na'im, Towards an Islamic Reformation, pp. ix and xii respectively). Also see Andrew March's comments in Islam and Liberal Citizenship, p. 291 n. 40 , where he admits that An-Na'im's views are (or would be) considered by mainstream Muslim scholarship to be heretical.

71 For the notion of 'private religion' and the role played by the modern state in its creation I am indebted to the stimulating paper by William T Cavanaugh, 'A Fire Strong Enough to Consume the House: The Wars of Religion and the Rise of the State', Modern Theology 11: 4 (1995), pp. 397-420.

72 Habermas describes the transformation involved here very well: 'Each religion is originally a 'worldview' or, as Rawls puts it, a 'comprehensive doctrine', in the sense that it lays claim to the authority to structure a form of life in its entirety. A religion that has become just one among several confessions must abandon this claim to comprehensively shape life. Under the conditions of pluralism the life of the religious community must differentiate itself from the life of the larger political community. A prevailing religion loses its political impact on society at large if the political order no longer obeys the religious ethos'. Jürgen Habermas, 'Intolerance and Discrimination', International Journal of Constitutional Law, 1, 1 (January 2003), 2-12 (here p. 6), emphasis in the original.

73 Although the difference still remains in the way they justify their respective positions and in the scope and aims of their respective projects.

74 Rawls, 'The Idea of Public Reason', p. 782 n. 46.

75 For this see Andrew March's works cited above.

76 This may come as a surprise to many considering all the genuine concerns about the ahistoricity of analytic philosophy and Rawls' own earlier work. I am not claiming that Rawls' actual exposition is historical, what I am saying is that it is informed by a particular reading of (and sensitivity to) history, especially western history of the last four-orso hundred years. It is a great example of a work which treats Quine's dictum of philosophizing from within or the immanent mode of thinking seriously. See Rawls, Political, pp. xiii-xxxiv. The whole argument depends on and is situated in the context of public culture of democracy (Rawls, 'Reply to Habermas', p. 135).

77 As noted earlier, this does not commit me in any way to a modus vivendi interpretation of the overlapping consensus or Rawls' political liberalism in general.

78 Rawls, 'Reply to Habermas', p. 135.

79 This totalizing streak is also internal to the extent that despite being limited to the political, within its own limited realm, it aspires for 'completeness' and is not content with any sort of partiality (Rawls, 'The Idea of Public Reason', p. 777). Also note that Rawls makes it clear that political liberalism encompasses the whole life, and not just the political realm (See Rawls, 'The Idea of Public Reason', p. 791ff.).

80 Of course, different comprehensive doctrines will require different levels of transformation in order to turn into reasonable doctrines; so, for example, a Christian comprehensive doctrine, I assume, requires more transformation and transfiguration in order to become a reasonable doctrine compared to, say, a Kantian worldview. But my argument above is not affected by the introduction of this nuance. Also note that Rawls realizes that a doctrine can be unreasonable in a particular aspect without being unreasonable as such: see ibid., p. 798 n. 80 .

81 Justification itself is required to give depth to consensus on political liberalism, but the specific mode of justification (that is, each and every citizen embedding political liberalism within their own doctrines or non-doctrines privately and internally) is to make sure that political liberalism does not muddy the waters by interfering in doctrines (or non-doctrines) unnecessarily.

82 Let's call it the fact of imperialism. One of the greatest hurdles to the development of indigenous versions of secularism among Muslims is the legacy of imperialism.

83 My argument should be read as a conceptual one and not an empirical one.

84 See, for example, Cavanaugh, "A fire strong enough to consume the house", and Leif Wenar, 'Political Liberalism: An Internal Critique', Ethics, 106 (October 1995), pp. 32-62.

85 Rawls, 'Reply to Habermas', p. 133.

86 Ibid., pp. 145 \& 147.

87 Ibid., p. 147.

88 Ibid, pp. $146 \& 148$.

89 Ibid., p. 146.

90 This does not imply a pragmatic or even a modus vivendi reading of political liberalism, but it can be plausibly argued that within an overall principled approach of Rawls there is a justified role for pragmatic concerns. My approach here, however, is different from, for example, John Horton's modus vivendi approach in that it emerges from 
within political liberalism itself (cf. John Horton, 'Toward a political Theory of Modus Vivendi', available at http:// www.ucl.ac.uk/spp/seminars/political-theory-downloads/PolTheoryofModusVivendi_UCL_.pdf, accessed on 15/10/ 2010).

91 However, Rawls accepts that, empirically speaking, the majority of citizens (and not all citizens) are reasonably expected to endorse political liberalism, and, furthermore, he also explicitly states that for stability one only needs 'enduring majority' (Rawls, 'Reply to Habermas', p. 147). As far as I can see, positively and conceptually speaking he does not provide any exceptions as far as participation in the full justification is concerned.

92 Here I am using 'reasonable' in the thin sense (negative sense) defined above. The context should make clear which sense of reasonable is meant.

93 This will also necessitate a different version of public justification for such doctrines (or their adherents), as public justification is intimately linked with the second level of justification in Rawls.

94 Sune Lćgaard notes that Rawls' distinction between stability for the right reasons and stability as a modus vivendi is not exhaustive. He suggests a broader distinction between stability for the right reasons and "mere stability', understood as factual stability' ('Feasibility and Stability in Normative Political Philosophy: The Case of Liberal Nationalism'. Ethical Theory and Moral Practice 9 (2009), pp. 399-416; here p. 408, emphasis in the original).

95 Not only on a practical level (which Rawls concedes) but also on a theoretical level.

96 From a liberal perspective, that is.

97 Such a notion of justification is implicit in March's works (mentioned above) on Islam and the possibility of this notion justifying liberalism. Although when I first wrote these lines I was unaware of March's work, his writings provide additional support for my conjecture; however, March writes as a firm adherent of political liberalism, whereas I have no such loyalty. I see political liberalism as one of the resources for political and philosophical discussion (which may or may not have implications for policy debates).

98 As March notes, Islam is vehement in its insistence on sticking to firm ethical standards when dealing with those outside its boundaries (let alone those inside it): ‘. . . even premodern Islamic legal discourses affirm a certain set of values and principles which prescribe very rigorous ethical standards for dealing with non-Muslims, within both Muslim and non-Muslim polities' (March, 'Islamic Foundations', p. 236).

99 Cf. March, 'Liberal Citizenship', pp. 379 and 380.

100 I should mention here that Rawls does not expect (in the empirical sense) that all citizens and all comprehensive doctrines will support or justify liberalism in his sense (see Rawls, 'The Idea of Public Reason', p. 806), but he does require (in the normative sense) all citizens and all comprehensive doctrines to justify liberalism fully. His schema does not provide any normative exceptions to the justification required. Those citizens and doctrines that empirically fail to justify liberalism (and failures of different degrees are expected and recognised), according to Rawls' schema, are categorised as 'unreasonable' commensurate with the level of failure.

101 This is required for the feasibility and plausibility of a possibility.

102 I would even go further and suggest that for the stability of a system, including a liberal system, even majority support is not necessary. What is needed is a critical mass, which might not be the majority of citizens in numerical terms. Support from important sectors, or from some mix of them, might be necessary (involving industrial, financial, military power, etc.) but those may not come remotely close to a majority of the population in numerical terms. I would also intuitively want to distinguish 'support' from 'acquiescence'. I would guess that there have been quite stable systems without majority 'support' but where there is general 'acquiescence'. Acquiescence can come from various sources, including general apathy, a general sense of hopelessness/powerlessness, or a general fear/terror of what might happen if one were to engage in opposition or try to organize opposition. But acquiescence can come more positively, for instance where the system, though does not 'thrill' some of its citizens, nevertheless fulfills their needs enough that they go along with it without actually 'supporting' it. This would more like passive support than mere apathy or helplessness.

103 Juergen Habermas, The Divided West, ed. and trans. Ciaran Cronin (Oxford, Polity, 2006), p. 10.

104 Forceful resistance is unreasonable, Rawls, 'The Idea of Public Reason', p. 766.

105 It is worth pointing out that this only pertains to the political in Rawls' sense. At the level of background culture, all doctrines and citizens would be exposed to the educational and cultural influences of liberal culture and institutions, and socialisation should do the work that Rawls' justificatory strategy aims to do at the political level. This would be a test of the efficacy of liberal culture and institutions. On socialization and its importance see Jürgen Habermas, 'Remarks on Legitimating through Human Rights', in Jürgen Habermas, The Postnational Constellation, ed. by Max Pensky (Oxford: Polity, 2001), pp. 113-129. For an excellent commentary on Habermas on this point see Farid Abdel-Nour, 'Farewell to Justification: Habermas, Human Rights, and Universalist Morality', Philosophy and Social Criticism 30: 1 (2004), pp. 73-96.

106 Even on the theoretical plane.

107 March, 'Liberal Citizenship', p. 381 n. 14, emphasis in the original.

108 With Lćgaard I take both feasibility and stability to be properties of political conceptions and not ideals in themselves; although feasibility is the necessary condition of stability it is not a sufficient condition in itself (Lćgaard, 'Feasibility and Stability', p. 406).

109 Rawls writes: '. . . we must each give up forever the hope of changing the constitution so as to establish our religion's hegemony, or of qualifying our obligations so as to ensure influence and success. To retain such hopes and aims would be inconsistent with the idea of equal liberties for all free and equal citizens' (Rawls, 'The Idea of Public Reason', p. 782.) 
110 Steve Ove Hansson and Gert Helgesson, 'What is Stability', Synthese 136 (2003), pp. 219-235 (here p. 221).

111 See Jürgen Habermas, 'Reconciliation through the Public Use of Reason', and 'Reasonable' Versus 'True', or the Morality of Worldviews', both in Jürgen Habermas, The Inclusion of the Other: Studies in Political Theory, ed. by Ciaran Cronin and Pablo De Greiff (Oxford: Polity, 2002), pp. 49-101. Rawls reply to Habermas is in Rawls, 'Reply to Habermas'.

112 Cf. Rawls, Political, pp. 150-172 and Rawls, 'The Idea of Public Reason', for example.

113 Rawls, Political, pp. 15-22. 'Political Society is closed; we come to be within it and we do not, and indeed cannot, enter or leave it voluntarily' (p. 136).

114 'Immigration is also a common fact but we can abstract from it to get an uncluttered view of the fundamental question of political philosophy. Of course, immigration is an important question and must be discussed at some stage. I surmise this is best done in discussing the appropriate relation between peoples, or the law of peoples, which I don't consider in these lectures' (Rawls, Political, p. 136 n. 4). In fact this is the only reference to immigration in Political Liberalism. In his The Law of Peoples: The Idea of the Public Reason Revisited (Cambridge, Mass; Harvard University Press, 1999) there is some discussion of the fact, but obviously in a totally different context (see pp. 8-9). 